\title{
Optimal Sizing Design for Hybrid Renewable Energy Systems in Rural Areas*
}

\author{
Yu Fu${ }^{1}$, Jianhua $\mathrm{Yang}^{1}$, and Tingting $\mathrm{Zuo}^{2}$ \\ ${ }^{1}$ College of Information and Electrical Engineering, China Agricultural University, \\ Beijing, 100083, P.R. China \\ \{fuyu-1986, yang.haag\}@163.com \\ ${ }^{2}$ Tianjin Electric Power Corporation, Tianjin, 300010, P.R. China
}

\begin{abstract}
Small-sized hybrid wind-hydro-solar power generation systems may be designed to solve the power supply problem in some rural areas. Optimal design models are developed to design the hybrid generation systems including battery banks and to provide the optimum system configuration. It is ensured that the annualized cost of the systems is minimized while satisfying the required loss of power supply probability. A genetic algorithm is used to find the optimum configuration. Moreover, four membership grades of the systems, such as the reliability, the economical efficiency, the complement and the environmental benefit, are created by a linearly-weighted fuzzy algorithm to search the configuration. The optimal algorithms are applied to a practical project. The optimal design of the project is gotten and analyzed, which shows that the complement and the environmental benefit are taken full advantage of, and the corresponding system cost is minimized with enough power supply reliability.
\end{abstract}

Keywords: hybrid renewable energy system, loss of power supply probability, genetic algorithm, linearly-weighted fuzzy algorithm.

\section{Introduction}

Wind, hydro and solar energy are inexhaustible, renewable and clean energy sources. Some remote areas cannot be supplied by large power grids; however, there are enough resources of wind, hydro and solar energy available. Therefore, hybrid power generation systems can be built by making full use of the complement of these nondepletable energy sources to solve the power shortage problem in the areas.

Present researches of hybrid power generation systems focus mainly on the combination of photovoltaic (PV) arrays and wind turbines [1, 2], and the best compromise point between system power reliability and system cost is rarely considered in their design. In this paper, the mathematical models of optimal sizing design for the smallsized hybrid power generation system are given. The wind, hydro and solar energy sources are used in the system. Based on the models, a genetic algorithm (GA) and a linearly-weighted fuzzy algorithm are used to get the optimum system configuration

Supported by National Key Technology R\&D Program for the 11th Five-Year Plan (2006BAJ04B03). 
that can achieve the required loss of power supply probability (LPSP) with a minimum annualized cost of system (ACS).

\section{Models of Hybrid System Components and Battery}

A hybrid wind-hydro-solar power generation system consists of PV arrays, wind turbines, hydro turbines, battery banks, an inverter, a controller, cables and other accessory devices. In order to predict the hybrid system performance, each component needs to be modeled and then the generation system can be evaluated to meet the load demand.

The models of three generation components of the system including wind turbines [3], hydro turbines and PV arrays [4] are proposed in Ref. [5]. Then, the output power at a given time can be calculated according to the weather data $[5,6]$.

The battery [7] can only be charged to rated capacity, and be limited by the maximum permissible depth of battery discharge when discharging. Therefore, modeling the charging-state of battery is necessary. At any time the state of battery is related to the previous state of charge and to the energy production and consumption situation of the system during the time from $t-1$ to $t$ [8]. During the charging process, when the total output of the generation units, i.e. the PV modules, the hydro generators and the wind generators, are greater than the load demand, the battery bank capacity available at time $t$ can be described by

$$
E_{b a t}(t)=E_{b a t}(t-1) \cdot(1-\sigma)+\left(E_{g}(t)-E_{L}(t) / \eta_{i n v}\right) \cdot \eta_{b a t} .
$$

where $E_{b a t}(t)$ and $E_{b a t}(t-1)$ are the battery bank capacity available at time $t$ and $t$ - 1 , respectively, $\eta_{b a t}$ is the battery efficiency, $\sigma$ is the self-discharge rate of the battery bank, $E_{g}(t)$ is the energy generated by the generation units, $E_{L}(t)$ is the load demand at time $t$, and $\eta_{i n v}$ is the inverter efficiency.

On the other hand, when the load demand is greater than the energy generated, the battery bank is in discharging state. Therefore, the battery bank capacity available at time $t$ can be expressed as

$$
E_{b a t}(t)=E_{b a t}(t-1) \cdot(1-\sigma)-\left[E_{L}(t) / \eta_{i n v}-E_{g}(t)\right] .
$$

At any time, the storage capacity is subject to the following constraints:

$$
E_{b a t \min } \leq E_{b a t}(t) \leq E_{b a t \max }
$$

where $E_{b a t \max }$ and $E_{b a t \min }$ are the maximum and minimum allowable storage capacity, respectively. $E_{\text {batmax }}$ can be taken as the nominal storage capacity $C_{b a t n}$, and $E_{\text {batmin }}$ can be given by

$$
E_{b a t \min }=D O D \times C_{b a t n} .
$$

where $D O D(\%)$ represents the maximum permissible depth of battery discharge. 


\section{Power Reliability Model Based on LPSP Concept}

LPSP $[8,9]$ is defined as the probability that an insufficient power supply results when the hybrid system, including the PV arrays, the wind turbines, the hydro turbines and the battery storage, is unable to meet the load demand. Values of LPSP range from 0 to 1 . A LPSP of 0 means that the load is always satisfied, and a LPSP of 1 means that the load is never satisfied. LPSP can be expressed as

$$
L P S P=\frac{\sum_{t=1}^{T}\left\{E_{L}(t)-\left[E_{g}(t)+E_{b a t}(t-1)-E_{b a t \min }\right] \eta_{\text {inv }}\right\}}{\sum_{t=1}^{T} E_{L}(t)} .
$$

where $\mathrm{T}$ is the operation time, normally $\mathrm{T}$ is one year.

When LPSP is computed, the input data set consists of daily or hourly solar irradiation on a horizontal surface, the mean values of the ambient temperature, the wind speed and the water current velocity, the load power demand during the year, the technical specifications of the system components, and so on.

\section{Economic Model Based on ACS Concept}

ACS [10] is composed of the annualized capital cost $C_{\text {acap }}$ and the annualized maintenance cost $C_{\text {amain }}$. The cost of five main components needs to be considered, such as the wind turbines, the hydro turbines, the PV arrays, the battery and the other devices. Then the ACS can be expressed as

$$
A C S=C_{\text {acap }}+C_{\text {amain }} .
$$

The annualized capital cost of each component takes into account the installation cost, and is calculated by

$$
C_{\text {acap }}=C_{\text {cap }} \cdot \frac{i \cdot(1+i)^{Y_{\text {proj }}}}{(1+i)^{Y_{p r o j}}-1}
$$

where $C_{c a p}$ is the initial capital cost of each component, $Y_{\text {proj }}$ is the component lifetime, $i$ is the annual real interest rate. The lifetime value $Y_{\text {proj }}$ of some devices can be referred to Ref. [11].

The annualized maintenance cost can be estimated by two different ways. First, under normal circumstances, the maintenance cost of wind turbines within service life is $20 \%$ to $25 \%$ of the total cost, while the hydro turbine is $10 \%$, the PV module is $5 \%$, and the battery is $10 \%$. Second, it can be considered to be a static value which depends on practical statistics. 


\section{System Optimization Model with GA}

GA is an advanced search and optimization method $[12,13]$ and is generally robust in finding global optimal solutions, particularly in multimodal and multi-objective optimization problems.

An optimization model is developed here to obtain the optimum size or the optimal configuration of a hybrid wind-hydro-solar system including a battery bank in terms of the LPSP technique and the ACS concept using GA. The flow chart of the optimization process is illustrated in Fig.1.

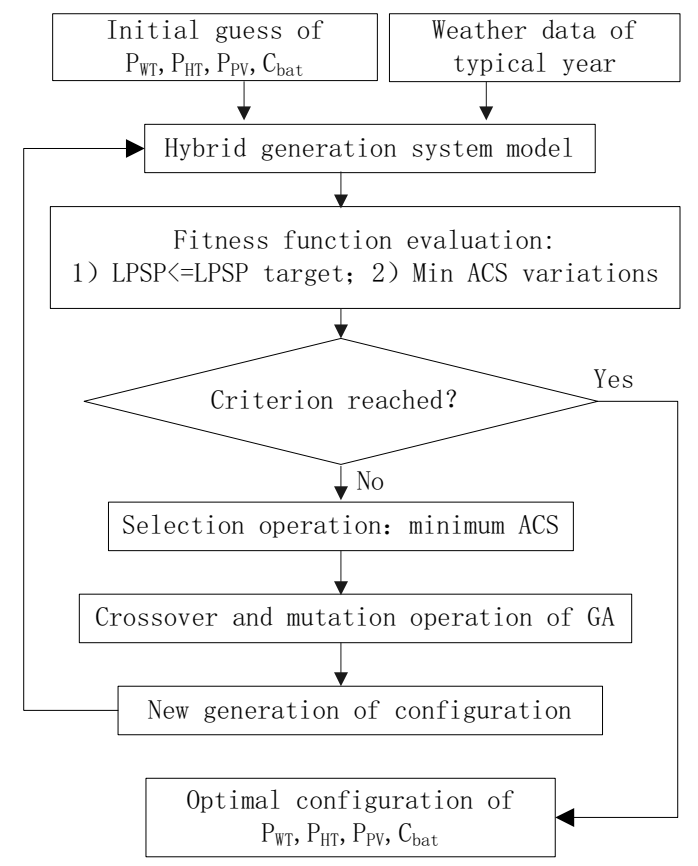

Fig. 1. Flow chart of the optimal sizing model using GA

The decision variables in the optimization process are the wind turbine power $P_{W T}$, the hydro turbine power $P_{H T}$, the PV module power $P_{P V}$ and the battery capacity $C_{b a t}$. Daily or hourly weather data of typical year includes the solar radiation on the horizontal surface, wind speed and water current velocity, and so on.

Combining the ACS with the LPSP based on a penalty function, the fitness function $F_{\text {fitness }}$ can be expressed as

$$
F_{\text {fitness }}=A C S+M \cdot[\max (0, L P S P-0.5 \%)]^{2} .
$$

where $M$ is penalty factor. 
The power outputs of the generation units are calculated by using their specifications as well as the weather data. The system configuration is then optimized by employing the genetic algorithm, which dynamically searches for the optimal configuration to minimize the fitness function. For each system configuration, LPSP of the system is examined to judge whether the requirement, i.e. LPSP target, can be satisfied. Then, the configuration of smaller fitness is subjected to the following crossover and mutation operations of GA in order to produce the next generation population until the criterion is satisfied. The optimal configuration can finally be found by achieving the lowest ACS while satisfying the LPSP requirement.

\section{System Optimization Model with Linearly-Weighted Fuzzy Algorithm}

The system optimization model based on linearly-weighted fuzzy algorithm [5, 14] considers four optimization objectives: the reliability, the economical efficiency, the complement and the environmental benefit. Each configuration has four membership grades according to the four objectives:

$$
r=\left(r_{0}, r_{1}, r_{2}, r_{3}\right)
$$

Different users have different requirements to the four objectives, so a set of weight is created:

$$
A=\left\{a_{0}, a_{1}, a_{2}, a_{3}\right\}
$$

Thus, the objective function is expressed as

$$
\min f=r_{0} \cdot a_{0}+r_{1} \cdot a_{1}+r_{2} \cdot a_{2}+r_{3} \cdot a_{3} .
$$

When the objective function is minimized, the optimal configuration is found.

The membership grade of reliability is the same as the LPSP, and the membership grade of environmental benefit is proposed in Ref. [5].

\subsection{Membership Grade Model of Economy}

Based on the ACS model, the cost per $\mathrm{kWh}$ of the hybrid generation system can be expressed as

$$
C_{k W h}=\frac{A C S}{E_{\text {year }}} .
$$

where $C_{k W h}$ is the power generation system cost per $\mathrm{kWh}, E_{y e a r}$ is the annual energy production of the hybrid generation system. 
The membership grade function of economy is:

$$
\mu_{1}=1-\frac{C_{k W h}}{C_{a c p}} .
$$

where $C_{a c p}$ is maximum cost per kWh acceptable to users.

\subsection{Membership Grade Model of Complementary}

The complementary of the hybrid system is measured by the difference in magnitude between the power consumption needed by the load and the total energy production generated by the generation units. The membership grade function of the complement can be expressed as

$$
\mu_{3}=\frac{\min \left(E_{\text {year }}, E_{\text {year } L}\right)}{E_{\text {year }}+E_{\text {year } L}} .
$$

where $E_{\text {yearL }}$ is the total load power consumption for one year.

\section{Result and Discussion}

The proposed methods are applied to design one demonstration project, which is built to supply power for a village committee in a remote village of a county, north China. The village is centered at $40^{\circ} 23^{\prime}$ north latitude and $116^{\circ} 52^{\prime}$ east longitude, $71.8 \mathrm{~m}$ above sea level. At the measured site, the effective wind power density is 43.26 $\mathrm{W} / \mathrm{m}^{2}$, the average annual wind speed is $2.37 \mathrm{~m} / \mathrm{s}$, the average annual solar radiation is $5545.6 \mathrm{MJ} / \mathrm{m}^{2}$. The useful waterfall height is $65 \mathrm{~m}$, the average water current velocity is $0.036 \mathrm{~m}^{3} / \mathrm{s}$ in the summer and autumn.

Based on the models of the hybrid wind-hydro-solar generation systems developed in this paper, the optimal configuration of the system fulfilling the requirements is found out. The calculation results are shown in Table 1, where method 1 is the algorithm based on GA, and method 2 is the algorithm based on the linearly-weighted fuzzy algorithm.

Table 1. Optimal sizing results

\begin{tabular}{l|c|c}
\hline & Results of method 1 & Results of method 2 \\
\hline Wind Turbine Power (W) & 2036.1 & $1000 \times 2$ \\
Hydro Turbine Power (W) & 2925 & 3000 \\
PV Array Power (W) & 731.5 & $32 \times 23$ \\
Battery Bank Capacity (Ah) & 469.2 & $120 \times 4$ \\
\hline ACS (RMB Yuan) & 8627.99 & 7265 \\
LPSP & $0.4991 \%$ & $0.4810 \%$ \\
\hline
\end{tabular}


Optimal sizing results of method 2 are the specifications of the products available from manufacturers. As shown in Table 1, similar optimal configurations of the two methods are gotten. But the annualized cost of system of method 2 is smaller because environment benefit is in consideration.

The design of the hybrid generation system is not simply a combination of wind, hydro and solar generation units. In order to make the most efficient use of energy resources and save investment, optimal methods in consideration of complementary characteristic among wind energy, solar energy and hydro energy should be used to find a scientific and reasonable configuration of each unit. At the same time, a battery bank is absolutely necessary to ensure system power reliability. Without it, the load demand can hardly be met continually.

The LPSP concept used in this study is a statistical parameter decided by users. It is clear that higher power reliable systems are more expensive than lower requirement systems. A smaller LPSP, i.e. higher reliability of the systems, results in high cost of the system and vice versa. Choosing an optimal system configuration according to the system power reliability requirement can save investment and avoid blind capital spending.

Moreover, the loss of load probability [15] may be used as the reliability criteria for the hybrid renewable energy system, too. Similar results can be gotten.

\section{Conclusions}

The optimum design sizing methods for the hybrid wind-hydro-solar systems based on the genetic algorithm and the linearly-weighted fuzzy algorithm are developed. The two methods can be used to search the system optimum configuration which can achieve the desired LPSP with minimum annualized cost of system. Taking requirements of the users and environmental benefit into consideration, the model based on linearly-weighted fuzzy algorithm is more adaptive to different designing condition.

The proposed methods are applied to design a demonstration project of the hybrid wind-hydro-solar system. With the daily measured field data of the studied project in one year, the energy contribution of the generation units, the battery working state and the energy balance of the system are investigated. The good complementary characteristic among wind energy, solar energy and hydro energy is found out.

\section{References}

1. Tina, G., Galliano, S., Raito, S.: Hybrid solar/wind power system probabilistic modeling for long-term performance assessment. Solar Energy 80(5), 578-588 (2006)

2. Markvart, T.: Sizing of hybrid PV-wind energy systems. Solar Energy 59(4), 277-281 (1996)

3. Rosen, A., Sheinman, Y.: The average output power of a wind turbine in a turbulent wind. Journal of wind Engineering and Industrial Aerodynamics 51(3), 287-302 (1994)

4. Datta, M., Senjyu, T., Yona, A., Funabashi, T., Kim, C.H.: Photovoltaic output power fluctuations smoothing methods for single and multiple PV generators. Current Applied Physics 10(2), 265-270 (2010) 
5. Zuo, T.-T., Yang, J.-H., Shao, B.-R.: Multi-objective optimal design of hybrid windhydro-solar power generation system. Journal of Agricultural Mechanization Research 21(9), 25-28 (2008) (in Chinese)

6. Yang, H.-X., Burnett, L., Lu, J.: Weather data and probability analysis of hybrid photovoltaic-wind power generation systems in Hong Kong. Renewable Energy 28(11), 18131824 (2003)

7. Guasch, D., Silvestre, S.: Dynamic battery model for photovoltaic applications. Progress in Photovoltaics: Research and Applications 11(3), 193-206 (2003)

8. Diaf, S., Diaf, D., Belhamel, M., Haddadi, M., Louche, A.: A methodology for optimal sizing of autonomous hybrid PV/wind system. Energy Policy 35, 5708-5718 (2007)

9. Ai, B., Yang, H.-X., Shen, H.: Optimum sizing of PV/wind hybrid system (I) CAD method. Acta Energiae Solaris Sinica 24(4), 540-547 (2003) (in Chinese)

10. Yang, H.-X., Zhou, W., Lou, C.-Z.: Optimal design and techno-economic analysis of a hybrid solar-wind power generation system. Applied Energy 86(2), 163-169 (2009)

11. Chen, Y.-M.: Fixed assets directory of State Grid Corporation. China Electric Power Press, Beijing (2005) (in Chinese)

12. Bala, B., Siddique, S.A.: Optimal design of a PV-diesel hybrid system for electrification of an isolated island-Sandwip in Bangladesh using genetic algorithm. Energy for Sustainable Development 13(3), 137-142 (2009)

13. Yang, H.-X., Zhou, W., Lu, L., Fang, Z.-H.: Optimal sizing method for stand-alone hybrid solar-wind system with LPSP technology by using genetic algorithm. Solar Energy 82(4), 354-367 (2008)

14. Jeong, K.S., Lee, W.Y., Kim, C.S.: Energy management strategies of a fuel cell/battery hybrid system using fuzzy logics. Journal of Power Sources 145(2), 319-326 (2005)

15. Deshmukh, M.K., Deshmukh, S.S.: Modeling of hybrid renewable energy systems. Renewable and Sustainable Energy Reviews 12(1), 235-249 (2008) 